\title{
Diagnosis of Acute Appendicitis in Adults: Role of a Simple Clinical Diagnostic Triad
}

\author{
Kassem Alubaidi, Malik Aikoye*, P. S. Basnyat \\ Department of General and Colorectal Surgery, East Kent Hospitals Nhs Trust, William Harvey Hospital, \\ Ashford, UK \\ Email: "achile_f@yahoo.com
}

Received 17 March 2016; accepted 12 April 2016; published 15 April 2016

Copyright (C 2016 by authors and Scientific Research Publishing Inc.

This work is licensed under the Creative Commons Attribution International License (CC BY). http://creativecommons.org/licenses/by/4.0/

(c) (i) Open Access

\begin{abstract}
Objectives: Acute appendicitis remains the commonest intra-abdominal surgical emergency. This study sought to identify the clinical factors that are most reliable in the diagnosis of acute appendicitis. Methods: This was a retrospective review of consecutive adult appendicectomies over a 6 months period. The frequency of different clinical parameters was assessed to determine the most reliable predictors of acute appendicitis. A simple triad of 3 of the most frequent clinical parameters was examined for diagnostic potential by calculating its sensitivity, specificity, positive predictive value and negative predictive value. Results: There were a total of 124 patients. The median age was 33 years while the gender distribution was 54 males to 70 females. The most common clinical parameters in the patients with appendicitis were right iliac fossa tenderness or peritonism $(\mathbf{1 0 0 . 0 \% )}$, anorexia $(\mathbf{7 8 . 8} \%)$, nausea $(75.9 \%)$, migratory abdominal pain i.e. pain migrating to right lower quadrant $(55.7 \%)$, tachycardia $(41.3 \%)$ and pyrexia i.e. body temperature of 37.8 degrees Celsius and above $(\mathbf{2 2 . 1 \% )}$ ). The simple triad of anorexia, right iliac fossa tenderness and migratory abdominal pain showed specificity for the diagnosis of acute appendicitis of $84.2 \%$ and sensitivity of $45.7 \%$. The positive predictive value of this triad was $94.1 \%$ while the negative predictive value was $21.9 \%$. Conclusion: Our study reveals that the positivity for this simple clinical triad strongly rules in the diagnosis of acute appendicitis. Its specificity and positive predictive value compares with the most reliable scoring systems for acute appendicitis in literature. Further approaches to diagnosis such as imaging and diagnostic laparoscopy should be considered when this triad is negative and appendicitis is suspected. This simple diagnostic approach allows for prompt diagnosis and treatment which expectedly would improve the morbidity associated with acute appendicitis.
\end{abstract}

\section{Keywords}

Acute Appendicitis, Diagnostic Triad

\footnotetext{
${ }^{*}$ Corresponding author.
} 


\section{Introduction}

Appendicitis remains the commonest intra-abdominal surgical emergency world-wide. It is commonest between the ages of 10 and 20 years [1] and shows a male preponderance. The diagnosis of this condition remains largely clinical [2].

Accurate diagnosis of acute appendicitis is important as it limits negative appendicectomy and avoids missed appendicitis. Negative appendicectomy is associated with increased morbidity while missed appendicitis risks serious appendicitis complications (gangrene, perforation and abscess) [3]. Like any medical condition, a detailed history and clinical examination is important in the diagnosis of appendicitis. Adjuncts in diagnosis include haematologic and biochemical investigations as well as radiological investigations.

The differential diagnoses vary from society to society as well as with the gender and age of the patient. They include; nephrolithiasis, crohn's disease, ovarian cyst, ovarian tortion, pelvic inflammatory disease, constipation, gallstone, cholecystitis, pancreatitis, hollow viscus perforation, urinary tract infection, gastroenteritis and terminal ileitis.

A number of clinical scoring systems for the diagnosis of acute appendicitis have been described.

Appendicectomy is the gold standard treatment for acute appendicitis.

\section{Methodology}

This was a retrospective review of consecutive adult appendicectomies over a 6 months period at the William Harvey Hospital. 4 Patients with incomplete or missing information were excluded.

Data was obtained using a proforma purposefully designed for study and was analysed using the excel spreadsheet.

The frequency of different clinical parameters in patients with appendicitis was assessed to determine the most reliable predictors of acute appendicitis. A simple triad of 3 of the most frequent clinical parameters was examined for diagnostic potential by calculating its sensitivity, specificity, positive predictive value and negative predictive value.

\section{Results}

A total of 128 consecutive appendicectomies were undertaken at our hospital during the study period in patients who are 18 years and above. 4 patients were excluded from the study on account of missing data giving a total of 124 patients for the study.

The median age of our patients was 33 years while the gender distribution was 54/70 (male/female). The frequency of appendicectomy by age group is shown in Figure 1 below.

The commonest clinical parameters in the patients with acute appendicitis are shown in Table 1.

The triad of migratory abdominal pain (migration to right lower abdominal quadrant) and the two commonest clinical parameters of anorexia and right iliac fossa tenderness or peritonism was positive in 51 patients.

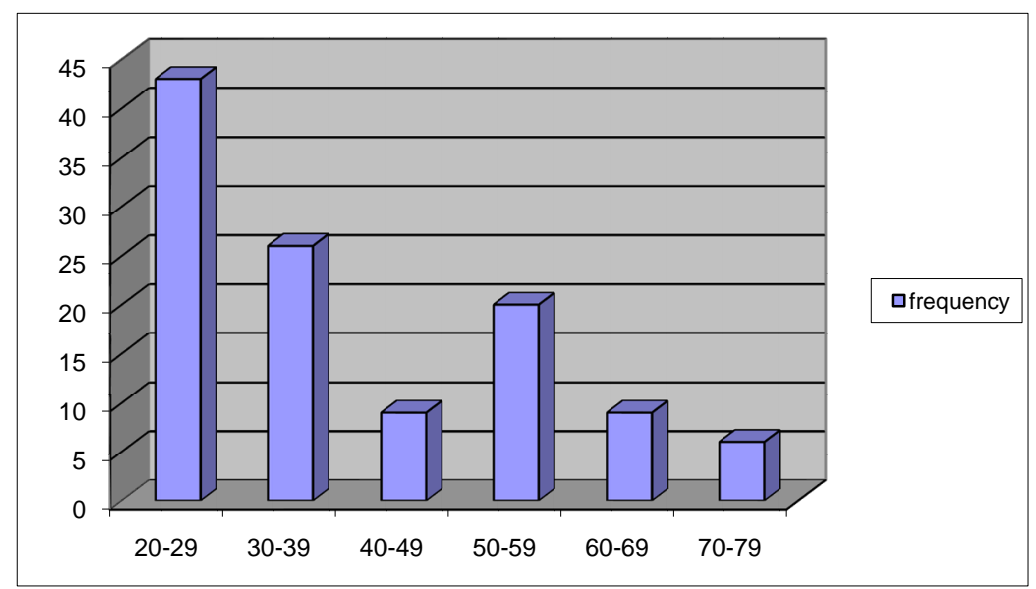

Figure1. Age distribution of appendicectomy patients. 
Table 1. Commonest clinical parameters in patients with acute appendicitis.

\begin{tabular}{cc}
\hline Clinical parameter & Frequency (Total = 104) \\
\hline RIF tenderness & $100.0 \%(\mathrm{n}=104)$ \\
Anorexia & $78.8 \%(\mathrm{n}=82)$ \\
Nausea & $75.9 \%(\mathrm{n}=79)$ \\
Migratory pain & $55.7 \%(\mathrm{n}=58)$ \\
Tachycardia (heart rate $>90 / \mathrm{min})$ & $41.3 \%(\mathrm{n}=43)$ \\
Pyrexia (temperature 37.8 degrees or above) & $22.1 \%(\mathrm{n}=23)$ \\
\hline
\end{tabular}

Migratory pain was included in the triad despite being less frequent than nausea as it has a well defined pathophysiology for acute appendicitis. Nausea is well known to be a non specific symptom. The presence of absence of positivity for this triad and the diagnosis of acute appendicitis is shown in the $2 \times 2$ table (Table 2).

The simple triad of anorexia, right iliac fossa tenderness and migratory abdominal pain showed specificity for the diagnosis of acute appendicitis of $84.2 \%$ and sensitivity of $45.7 \%$. The positive predictive value of this triad was $94.1 \%$ while the negative predictive value was $21.9 \%$.

\section{Discussion}

A cheap and easy to use diagnostic tool will allow for prompt diagnosis and the avoidance of unnecessary exposure to anaesthesia and surgery. It also will be economically helpful as radiological investigation and diagnostic laparoscopy can be reserved for patient whose diagnosis remains uncertain.

Increasing reliance on imaging (CT scanning, Ultrasound and MRI) has increasingly discouraged good clinical practice. There is the real risk of radiation induced malignancies especially in the younger patients. In the developing world a simple and reliable diagnostic approach would be of immeasurable benefit as it would save the cost of unnecessary investigations reserving these investigations for other condition as well for patients whose diagnoses remain uncertain.

Careful history taking would elicit the important symptoms of anorexia and migratory abdominal pain and simple examination of the abdomen would elicit tenderness and or peritonism.

Migratory pain has been described as the best individual predictor of acute appendicitis [4]. Initially the pain of acute appendicitis is generalised or central in keeping with the innervation of the appendix [5] but as inflammation progresses to involve parietal peritoneum the pain localises to the right iliac fossa [6]. The presence of migratory abdominal pain is significant [7]. It has been shown to be associated with a high likelihood ratio of acute appendicitis $(\mathrm{LR}+=3.1,95 \% \mathrm{CI}=2.4-4.2)[8]$.

The popular ALVORADO score contains a multiple of parameters which would need remembering. It is the best clinical appendicitis scoring systems available [9]. It includes 8 parameters and has a maximum score of 10. A patient with score of 7 to 8 has probable appendicitis while a patient with 9 - 10 has very probable acute appendicitis. Patients with scores 7 and above are offered appendicectomy. Sensitivity and specificity for this scoring system has been reported as $58.9 \%$ and $85.7 \%$ respectively [10].

Our study results suggest that this simple triad of anorexia, right iliac fossa tenderness and migratory pain finds role in "ruling in" appendicitis i.e. a positive triad screen cannot be ignored considering its remarkably high specificity and positive predictive value. A negative triad, on the other hand needs to be investigated further by more detailed history and possibly imaging or diagnostic laparoscopy.

While the reliability of these parameters taken in isolation may be small when the triad is present the diagnostic accuracy is significant.

Computer aided diagnosis of appendicitis has not been shown to be better than clinical diagnosis [11].

Ultrasound diagnosis of appendicitis shows variable performance with a sensitivity range of $44 \%-100 \%$ and a specificity range of $47 \%$ - 99\% [12]. This wide variability has been attributed to operator skill, obesity, anatomic variants in addition to previous abdominal operations. CT imaging shows sensitivity and specificity up to 95\% [13]. Pickhardt however showed that the sensitivity and specifity of CT scanning for appendicitis could be as high as $98.5 \%$ and $98 \%$ respectively [14].

In the proportion of patients where careful assessment of the patient does not yield diagnosis imaging should be employed to further assess the patient. 
Table 2. A $2 \times 2$ table relating triad positivity/negativity with histology of appendicitis.

\begin{tabular}{cccc}
\hline & Appendicitis & Negative appendicitis & Total \\
\hline Triad positive & 48 & 3 & 51 \\
Triad negative & 57 & 16 & 73 \\
Total & 105 & 19 & 124 \\
\hline
\end{tabular}

\section{Conclusion}

A simple diagnostic approach allows for prompt diagnosis and treatment which expectedly would improve the morbidity associated with acute appendicitis. This triad shows the important combination of high specificity and positive predictive value in the diagnosis of acute appendicitis.

\section{References}

[1] Addiss, D.G., Shaffer, N., Fowler, B.S. and Tauxe, R.V. (1990) The Epidemiology of Appendicitis and Appendectomy in the United States. American Journal of Epidemiology, 132, 910-925.

[2] Humes, D.J. and Simpson, J. (2006) Acute Appendicits. BMJ, 333, 530-534. http://dx.doi.org/10.1136/bmj.38940.664363.AE

[3] Andersson, R.E. (2007) The Natural History and Traditional Management of Appendicitis Revisited: Spontaneous Resolution and Predominance of Prehospital Perforations Imply That a Correct Diagnosis Is more Important than an Early Diagnosis. World Journal of Surgery, 31, 86-92. http://dx.doi.org/10.1007/s00268-006-0056-y

[4] Anderson, R. (2004) Meta-Analsis of the Clinical and Laboratory Diagnosis of Appendicitis. British Journal of Surgery, 91, 28-37. http://dx.doi.org/10.1002/bjs.4464

[5] Klein, K. (1995) Approach to the Patient with Abdominal Pain. In: Yamada, T., Ed., Textbook of Gastroenterology, Vol. 1. JB Lippincott Company, Philadelphia, 750-771.

[6] Silen, W. (1991) Cope’s Early Diagnosis of the Acute Abdomen. Oxford University Press, New York.

[7] Yeh, B. (2008) Evidence-Based Emergency Medicine/Rational Clinical Examination Abstract. Does This Adult Patient Have Appendicitis? Annals of Emergency Medicine, 52, 301-303. http://dx.doi.org/10.1016/j.annemergmed.2007.10.023

[8] Wagner, J.M., McKinney, W.P. and Carpenter, J.L. (1996) Does This Patient Have Appendicitis? JAMA, 276, 15891594. http://dx.doi.org/10.1001/jama.1996.03540190061030

[9] Ohmann, C., Yang, Y.Q. and Franke, C. (1995) Diagnostic Scores for Acute Appendicitis. Abdominal Pain Study Group. European Journal of Surgery, 161, 273-281.

[10] Nanjundaiah, N., Mohammed, A., Shanbhag, V., Ashfaque, K. and Priya, S.A. (2014) A Comparative Study of RIPASA Score and ALVARADO Score in the Diagnosis of Acute Appendicitis. Journal of Clinical and Diagnostic Research: JCDR, 8, NC03-NC05. http://dx.doi.org/10.7860/JCDR/2014/9055.5170

[11] Van Way, C.W., Murphy, J.R., Dunn, E.L., et al. (1982) A Feasibility Study of Computer Aided Diagnosis in Appendicitis. Surg Gynecol, 155, 685-688.

[12] Pinto, F., Pinto, A., Russo, A., Coppolino, F., Bracale, R., et al. (2013) Accuracy of Ultrasonography in the Diagnosis of Acute Appendicitis in Adult Patients: Review of Literature. Critical Ultrasound Journal, 5, S2. http://dx.doi.org/10.1186/2036-7902-5-S1-S2

[13] Petroianu, A. (2012) Diagnosis of Acute Appendicitis. International Journal of Surgery, 10, 115-119. http://dx.doi.org/10.1016/j.ijsu.2012.02.006

[14] Pickhardt, P.J., Lawrence, E.M., Pooler, B.D. and Bruce, R.J. (2011) Diagnostic Performance of Multidetector Computed Tomography for Suspected Acute Appendicitis. Annals of Internal Medicine, 154, 789-796. http://dx.doi.org/10.7326/0003-4819-154-12-201106210-00006 